\title{
Dere ağzı hidrodinamiğinin 3 boyutlu modellenmesi: Karışım ve tabakalı akım durumları
}

\author{
Ahmet Ozan ÇELİK*, Volkan KİRIÇÇi \\ Anadolu Üniversitesi Mühendislik Fakültesi, İnşaat Mühendisliği Bölümü, 2 Eylül Kampüsü, Eskişehir. \\ Geliş Tarihi (Recived Date): 23.06.2017 \\ Kabul Tarihi (Accepted Date): 18.08 .2017
}

\section{Özet}

Dere ıslahı çalışmalarının tasarım süreçlerinde, dere ăgzı yakınlarında ve haliçlerde geleneksel metotların karakterize edemediği ve etkin sonuç vermediği durumlar yaşanabilir. Bunun sebebi olarak tek boyutlu ampirik denklemlerin tabakal akımda veya karışım bölgesinde olayın fiziğini yansıtamaması gösterilebilir. Bir dere ağzl çıkışı yakınlarında tabakalı bir akım durumu olduğu varsayıldiğında, akım üst bölgesinde tabakalanan tatl su katı cidarla temas halinde olmayacak ve böylelikle taban pürüzlülü̈̆̈̈, kanal boyutlandırllması gibi hesaplamalarda etkinliğini yitirecektir. Bu durumda boyutlandırma için (kullanılan ama geçerliliği olmayan " $n$ " yardımıyla) Manning denkleminden elde edilecek olan hidrolik yarlçap gerçekçi olmayacaktır. Etkin sonuçlar alınamadı̆̆ durumlarda ise gereğinden daha büyük boyutlandırmalar ya da yetersiz kalabilecek kesitler ortaya çıkabilmektedir. Bu durum taşkınlara ve dolayısıyla geri dönüşü olmayan mal ve can kayıplara yol açabilmektedir. Riva Deresi'nde meydana gelen taşkınlar bu duruma verilebilecek bir örnektir. Bu çalışmada söz konusu dere ağzındaki tatlı-tuzlu su karışım bölgeleri sayısal olarak modellenmiş ve bu modelde gerçeğe yakın kesit ve debiler kullanılmıştır. 3 farklı senaryoda karşılaştırmalı değerlendirme yapılarak kesit tasarımında problem yaratan durumlar belirlenmiştir. Uygulanan Hesaplamalı Aklşkanlar Dinamiği (HAD) modelinin sonuçları ortaya konularak modelin yeterlilikleri ve geliştirilmesine yönelik yorumlar da değerlendirilmiştir.

Anahtar Kelimeler: Dere ăgzı, haliç, HAD, karışım, tabakalı akım

\footnotetext{
*Ahmet Ozan ÇELIK, aocelik@ anadolu.edu.tr, http://orcid.org/0000-0002-8770-2894

Volkan KİRIÇÇİ, vkiricci@ anadolu.edu.tr, http://orcid.org/0000-0001-8856-2021
} 


\title{
3D modeling of rivermouth hydrodynamics: Mix and stratified flow cases
}

\begin{abstract}
The design stages in river restoration work may encounter situations such as mix or stratified flow regions, river mouths or estuaries where conventional methods can not characterize the flow or be effective. This is due to the fact that one dimentional empirical equations fail to represent the physics of this phenomenon. That is, for instance for a stratified flow near a river mouth, the fresh water flowing on the top layer (above the denser saline water) will not be in contact with the bed, as a result the bed roughness will no longer be effective in design calculations of channel cross-section. Consequently, the back calculations of channel sizing from the hydraulic radius in the Manning equation will not be realistic. In such ineffective cases the calculations may result in unnecessarily large or inadequate cross sections. This leads to irreversible losses. Riva River can be considered as an example to such river mouths. In this study, the saline-fresh water mix region near the mouth of the questioned river has been modelled using realistic cross sections and discharge values. The problematic approaches have been identified using 3 different benchmark scenarios. The comments regarding the detailes of the employed computational fluid dynamics model have been also presented.
\end{abstract}

Keywords: River mouth, estuary, CFD, mix, stratified flow

\section{Giriş}

Dere ağzı (ya da daha genel tanımıyla haliç), tatlı suyla tuzlu suyun buluştuğu dinamik bir akışkan sistemidir. Bu bölgelerde karışımın oluşması veya karışımın gözlenmediği tabakalı akıma geçiş, deşarj ve akışkanların karakteristiklerine ve ayrıca yerel batimetriye göre değişkenlik gösterebilir. Bu değişkenliğin anlaşılması ve modellemesi zor olduğu gibi bölgesel verilere dayalı, zahmetli arazi ve laboratuvar incelemelerini de gerektirmektedir. Dere ağızlarındaki akım hidrodinamiğinin ve özellikle tatl1-tuzlu su karışımının (oluşması halinde) bilinmesi birkaç açıdan önemlidir [1].

Taşkın kontrolü, bilindiği gibi dere ağızlarında etkin bir şekilde uygulanamamaktadır. Bunun sebepleri karışım bölgelerinin dere içinde kalması ve tasarım parametrelerinin ve o bölgedeki akımın karmaşık olması gibi genel, ya da ağza yakın bölgelerde sıfır ya da negatif kanal eğimi gibi çok özel haller olabilir. Her durumda, tasarlanan kesitler, taşkın durumunda istenen şekilde çalışmayabilir.

Haliç bölgelerinde oluşan bu tür akım davranışlarının çevresel etkileri de bulunmaktadır. Deniz çevresi kirliliğine etki eden faktörlerden birisi nehir deşarjlarıdır. Deniz kıyılarının ve haliç bölgelerinin sağlığı ve sürdürülebilir ekolojik yapısı, nehir deşarjları ile gelebilecek kirlilik unsurlarının saçılımını (dispersion) kontrol edilebilmesi ile sağlanabilir. $\mathrm{Bu}$ da ancak haliç bölgelerindeki tatlı su deşarjı ve onunla taşınan maddelerin, deniz suyu ile karışımının anlaşılması ve doğru karakterize edilebilmesi ile mümkün olacaktır. Bunlara ek olarak, burada sözü edilen karışım ve tabakalı akım 
konuları, atık su ve arıtma suyu deniz deşarjlarının tasarımında da sıkça karşılaşılan ve anlaşılması gereken durumlardır [1-3].

Dere ağzı ve haliç gibi doğal su gövdelerinin dengesi membadan taşınan ve bu bölgelerde biriken katı madde miktarı ile doğrudan alakalıdır. Katı madde taşınımı akım kontrollü bir süreçtir ve oldukça karmaşık dere ağzı karışım ve tabakalı akım bölgelerinde akım davranışını belirleyebilmek, katı madde dengesi hakkında yorum yapabilmek için oldukça önemlidir [3, 4].

Söz konusu akımların nümerik olarak modellenmesi durumu için karışmayan sıvılara özel modelleme teknikleri literatürde kullanılmıştır. Abdolkarimi ve Ganji [5] ticari statik karıştırıcı modellemesinde 2 fazlı Eulerian modeli kullanmış ve bu tür cihazların tasarımında HAD metodunu etkin bir şekilde değerlendirmişlerdir. Georgulas ve diğ. [6] sayısal modelleme yöntemi ile farklı akışkanları ayrı ayrı çözerek ve birbirleri ile olan etkileşimlerini (two-way interaction) dikkate alarak 3 boyutlu, geniş ölçekli, çok fazlı bir çözüm gerçekleştirmiştir. Benzer çalışmalar, ticari kodlar yardımı ile literatürde yapılmaya devam etmekte ve bu konuda örnekler çoğaltılabilmektedir [7-10]. Birçok karışım modeline göre Eulerian-Eulerian çok fazlı yaklaşımları, her farklı sıvı için ayrı momentum çözümü sunarak diğer karışım modellerine göre daha hassas çözüm üretebilmektedir. Bu yaklaşım ile dispersion modelleri, akışkan momentum denklemleri ile eşleştirilerek dere ağzı bölgelerinde katı madde taşınımı da incelenebilmektedir [69]. Eulerian-Eulerian çok fazlı HAD çözümüne ait teori Bombardelli ve diğ. [2] ve Ofei ve diğ. [4] tarafından yapılan çalışmalarda sunulmaktadır ve burada tekrarlanmayacaktır.

$\mathrm{Bu}$ çalışmada dere ağzı bölgelerinde yapılması muhtemel tasarımlarda etkin olan akım koşulları ve parametreleri, hesaplamalı akışkanlar dinamiği (HAD) yöntemi kullanılarak incelenmiştir. Dere ağzı bölgelerindeki dere yataklarında, tatlı ve tuzlu su gibi farklı yoğunluklara sahip akışkanların oluşturduğu akım koşulları ve meydana gelen karmaşık akımın, taşkın kontrol yapılarının tasarımı üzerindeki etkileri, oluşturulan bilgisayar destekli sayısal model yardımıyla farklı senaryolar uygulanarak değerlendirilmiştir. Uygulanan model çok fazlı olup ( 2 fazlı), tatlı su, tuzlu su ve hava olmak üzere üç farklı akışkandan oluşmaktadır. Ayrıca uygulanan model zamana bağlı çözüm (transient solution) içermektedir.

Kanal geometrisi ve akım parametreleri gerçekçi verilere yakın tutularak ölçeklendirilmiş ve akım, üç boyutlu olarak, HAD metodu ile ANSYS-CFX yazılımı kullanılarak çözümlenmiştir (uygulanan yöntemin aşamaları için bkz. Şekil 1). Kullanılan program dâhilinde uygulanan metodun temel aşamaları aşağıdaki şekilde gösterilmiştir.

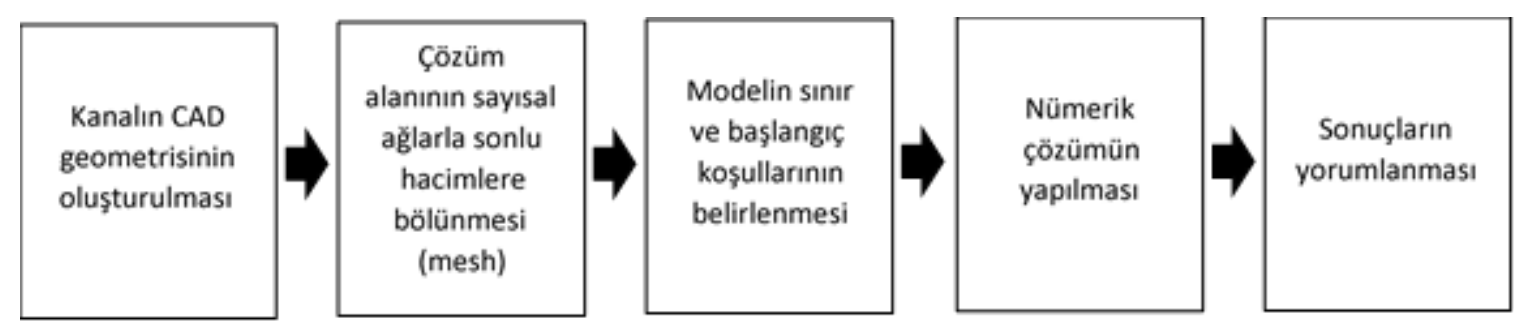

Şekil 1. Tipik bir HAD analizinin aşamaları. 
$\mathrm{Bu}$ çalışmanın amacı, sayısal model yardımı ile karşılaştırmalı bir değerlendirme yapmak ve geleneksel taşkın kanalı tasarım yöntemlerinin öngöremediği durumları tespit etmektir. Gerçekleştirilen sayısal analize ait detaylar metot kısmında açıklanmıştır.

\section{Metot}

Bu çalışmada, Riva Deresi benzeri bir dere ağzının bazı özellikleri sayısal olarak çalışılmıştır. Çalışma alanı ile ilgili detaylar DSİ 3. Şube Müdürlüğü'nden temin edilmiştir. Ancak söz konusu dere ağzı tamamen orijinaline uygun modellenmemiş olup bu bölgeye ait bazı karakteristik özellikler, temsili olarak daha az karmaşık bir kanal geometrisine uygulanmıştır. Bunu yaparken de amaç, bu özelliklerin izole edilerek taşkın kontrolü ile ilgili parametrelerine etkilerini belirleyebilmektir.

Kanal, boyuna kesitte $44 \mathrm{~m}$ uzunlukta ve akım doğrultusu boyunca üç bölgede farklı eğime sahip trapez kesitli olarak modellenmiştir. Geometrik boyutlar, eğimler ve görünümler Şekil 2'de gösterilmiştir. Modellenecek dere ağzında deniz seviyesi dere taban kotunun üstünde kalacak şekilde karaya doğru bir miktar girmiş kabul edilecek ve karışım ve tabakalı akım durumu taşkın yatağı içerisinde gerçekleştirilecektir. Bu durum, taşkin konusunda problemli olan Riva Deresi bölgesinin karakteristik bir özelliğidir.

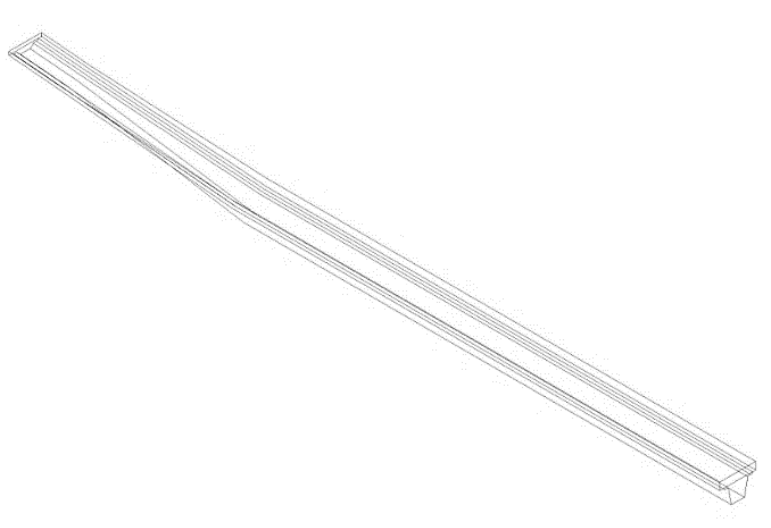

Şekil 2. Kanal geometrisi genel görünüm.

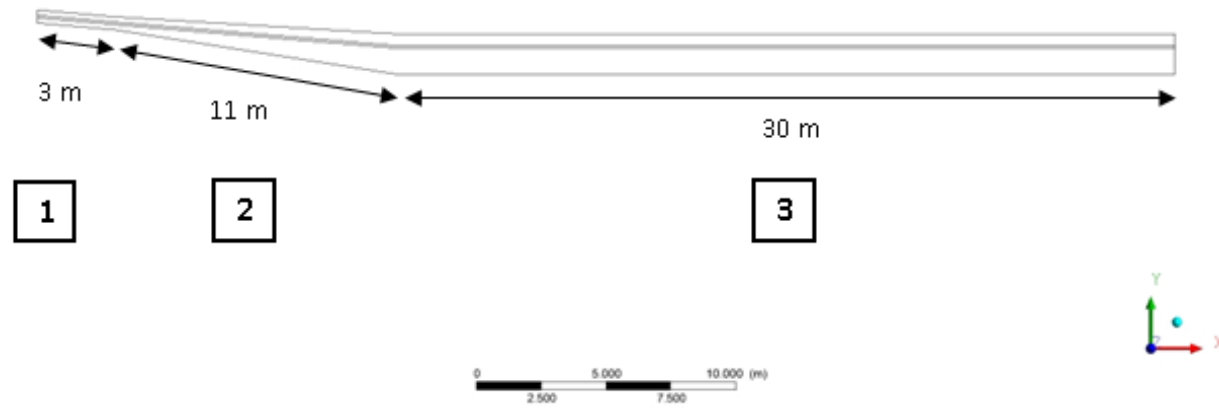

Şekil 3. Kanal geometrisi boy kesit görünüm, 1. bölüm eğim: $5^{\circ}, 2$. bölüm eğim: $9^{\circ}, 3$. bölüm eğim: $0.005^{\circ}$. 


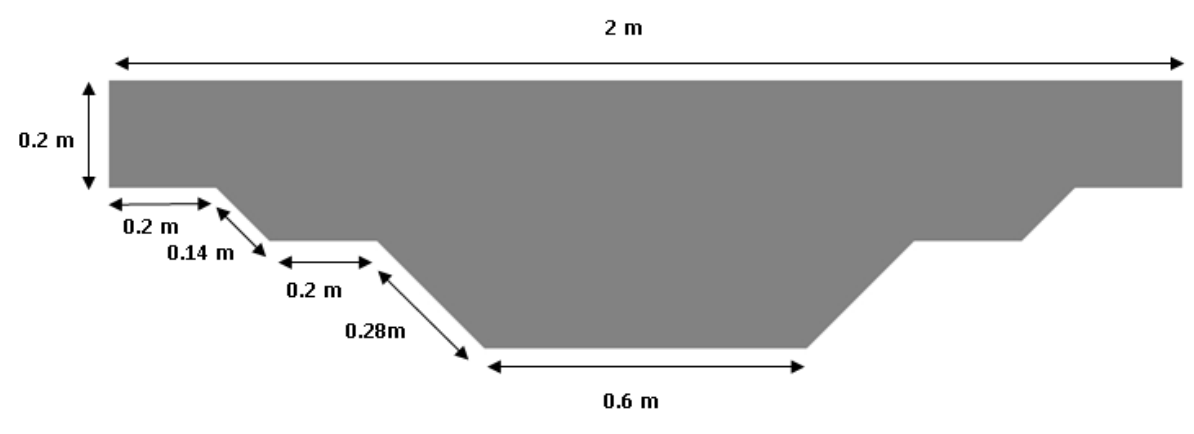

Şekil 4. Kanal geometrisi giriş kısmının en kesit boyutları.

Geometrisi belirlendikten sonra çözüm (akım) alanı, sonlu hacimlere bölünerek sayısal bir ağ (mesh) oluşturulmuştur. Burada, akım probleminin yapısı ve model ölçeği göz önüne alınarak mesh boyutları belirlenmiş olup, gerekli görülen bölgelerde (sıklaştırma uygulanarak toplamda yaklaşık 200,000 elemandan oluşan bir sayısal çözüm ağı oluşturulmuştur. Şekil 5'de uygulanan mesh ile ilgili görseller verilmiştir.

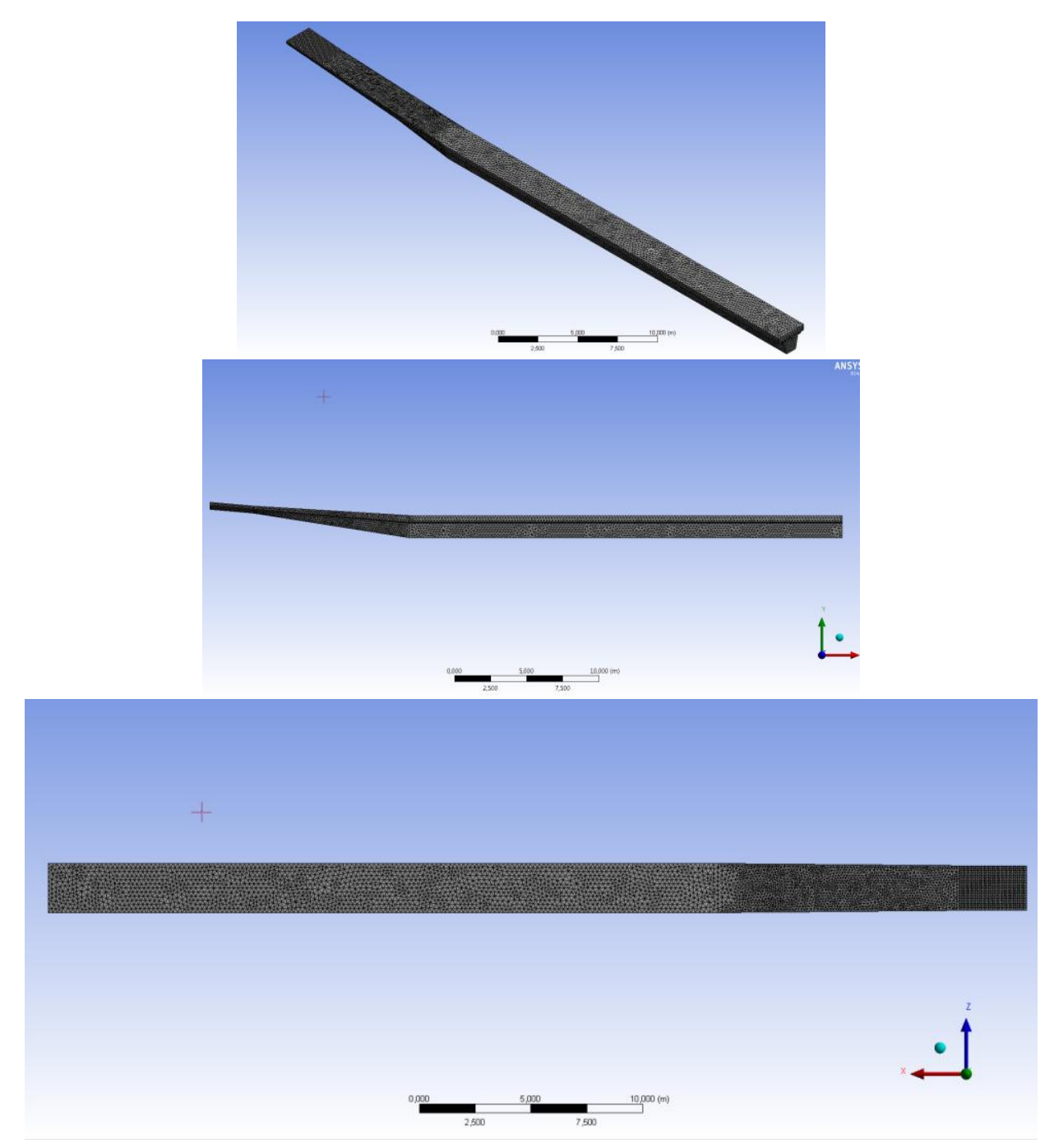

Şekil 5. Uygulanan sayısal ağ, sırası ile genel yan ve üst görünümler. 
HAD çözümlerinin sayısal ağa bağımlılığı (mesh dependence) ayrıca incelenmiş ve uygulanan ăg yapısı, ağ bağımsızlığı anlamında ön bir çalışma ile irdelenmiştir. Üç farklı ortalama ağ elemanı boyutu ile (küçük, orta, büyük) uygulanan ağ yapılandırması için ayrı ayrı su ve havadan oluşan serbest yüzeyli çözümler gerçekleştirilmiştir. Bu çözümler sonucunda her bir modelin kendi içinde ağ bağımlılığına bağlı parametrik değişim göz önünde bulundurulmuştur. Burada alansal ortalama taban kayma gerilmesi, kontrol parametresi olarak seçilmiş ve aynı model tekrar çalıştırılarak sadece ağ yapısından kaynaklı farklılık belirlenmiştir. Buna göre küçük boyutlu ağ elemanlarından oluşan yapılandırma için kayma gerilmesindeki değişim \% 1,8 olarak en düşük sapmayı vermiş ve çalışmaya bu ağ yapılandırması ile devam edilmiştir. Ayrıca ă̆ kalitesi ile ilgili bir gösterge olan skewness (çarpıklık), ortalama 0.20 civarında kalarak kaliteli bir ağ yapısı oluşturulduğundan emin olunmuştur.

Model geometrisi uygun sayısal ağ ile sonlu hacimlere ayrıldıktan sonra kanaldaki akım parametreleri ve buna bağlı uygun başlangıç ve sınır koşulları belirlenmiştir. Sınır koşullarının mertebe olarak doğruluğu, çözümün hassasiyetini etkileyen bir durumdur. Modelde uygulanan sınır koşulları (inlet, outlet, opening, wall; sırası ile giriş, çıkış, açıklık ve duvar) Şekil 6'da gösterilmiştir [6]. Kanalda oluşan akım üç farklı durum için $0.45 \mathrm{~m}^{3} / \mathrm{s}$ sabit giriş debisi altında zamana bağlı olarak ayrı ayrı çözümlenerek incelenmiştir. Her bir durum için zaman aralıkları 0,05 saniye olan toplam 64 saniyelik çözümler yapılmıştır. Her bir zaman aralığ 1 için maksimum 10 iterasyon uygulanmıştır. Kanal ciradında $2 \mathrm{~mm}$ pürüzlülük değeri uygulanmış ve türbülans modeli olarak iki denklemli Shear Stress Transport (SST) modeli seçilmiştir. Bu model cidar yakınlarında farklı, serbest kayma bölgesinde ise farklı türbülans kapanma denklemleri uygulamakta ve Reynolds ortalamalı modeller arasında cidar etkilerini en iyi yansitan modellerden biri olarak değerlendirilmektedir [2, 11-12]. Çok fazlı akım analizlerinde, hava, su ve tuzlu su etkileşimi Volume of Fraction (VOF) modeli tercih edilerek çözümlenmiştir. Uygun ağ yapısı ve doğru sınır koşulları, yakınsama ve diğer kriterlere de bağlı olarak, farklı tür sıvıların karışımının söz konusu olduğu üç boyutlu akım benzetimlerinde başarı ile uygulanabilmektedir. Bahsedilen kriterler ve deneysel doğrulama ile ilgili olarak Bombardelli ve diğ. [2] çalışması incelenebilir.

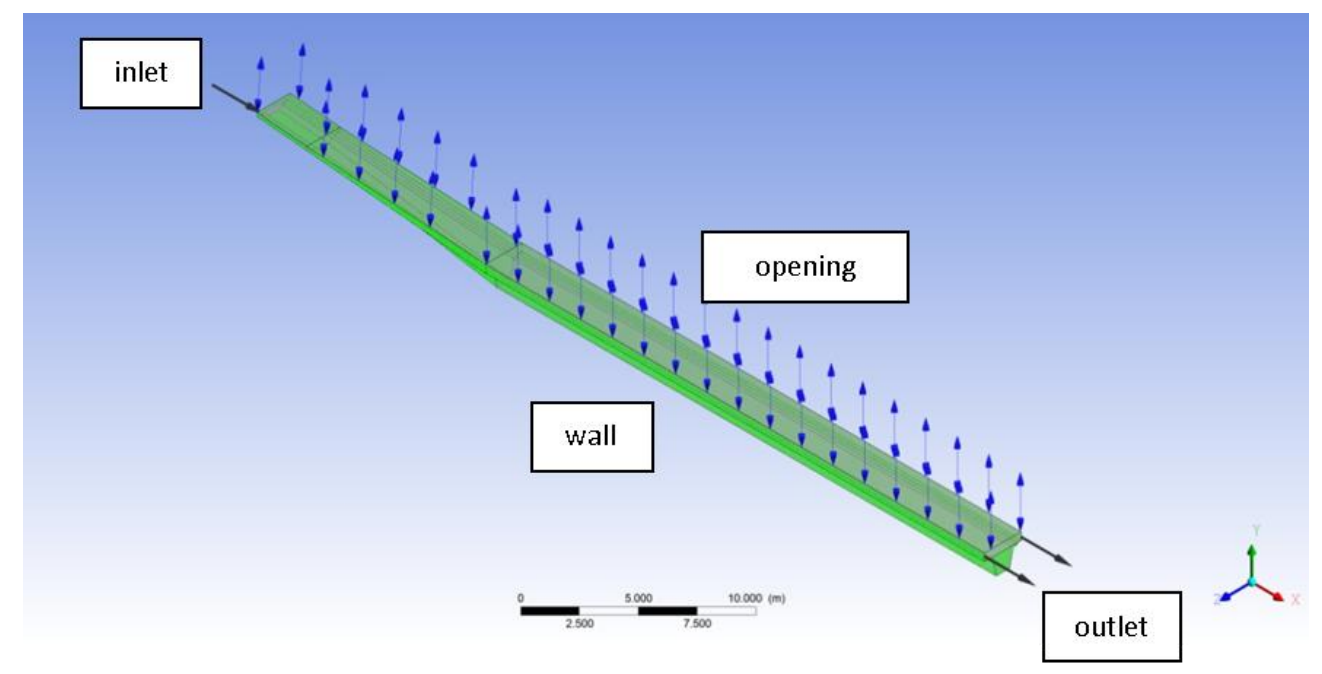

Şekil 6. Model sınır koşulları 
Açık su kanallarının tasarımında yaygın olarak ampirik Manning denklemi kullanılmaktadır (Denklem 1). Manning denkleminde kanal malzemesinin özelliklerine bağlı olarak değişen değerler alan pürüzlülük katsayısı ifadesi seçilerek belirli debi koşulları altında kanalın karakteristik boyutları belirlenmektedir.

$Q=\frac{a}{n} A R^{2 / 3} S^{1 / 2}$

Burada, Q debi $\left(\mathrm{m}^{3} / \mathrm{s}\right)$, a birim düzeltme katsayısı (SI birim sistemi için 1), A sslak alan $\left(\mathrm{m}^{2}\right)$, R hidrolik yarıçap $(\mathrm{m})$ ve $\mathrm{S}$ kanal taban eğimidir.

Dere ağzı bölgeleri gibi farklı yoğunluktaki sıvıların (tatlı/tuzlu su) bir arada bulunabileceği karmaşık akım koşullarına sahip ve oldukça düşük taban eğimi bulunan bölgelerde Manning denklemi ile yapılan tasarımların yetersiz kalabildiği görülmüştür. $\mathrm{Bu}$ bağlamda, kanalın boş olduğu, kanal boyunca tatlı suyun bulunduğu ve akarsuyun deniz suyuna karıştığ davranışının ve kanal cidarında oluşan kayma gerilmelerinin nasıl değiştiği üç farklı durum için çözümlenmiştir. Aşağıda bu üç farklı durum detaylandırılmıştır.

1. Senaryo: Kanalın başlangıçta boş olduğu ve kanala sadece tatlı su girişinin olduğu durumdur. $\mathrm{Bu}$ durum, Manning denkleminin geçerli olduğu durumdur ve ayrıca diğer senaryoları değerlendirmek için referans olarak kullanılacaktır.

2. Senaryo: Kanalda başlangıçta belirli bir derinlikte tatlı suyun bulunduğu ve kanal girişinde tatlı su akımının bulunduğu durumdur. Bu durumda ise aynı akışkanın karışımı söz konusu olacak ancak farklı yoğunluklarda ancak karışabilen sıvılardaki karmaşık durum geçerli olmayacaktır.

3. Senaryo: Kanalda başlangıçta belirli bir derinlikte tuzlu suyun bulunduğu ve kanal girişinde tatlı su akımının bulunduğu durumdur. Uygulanacak bu son durum en karmaşık ve gerçekte Riva Deresi'nde yaşanan koşullara en yakınıdır. Bu koşul, yoğun dip akım (dense underflow) olarak da adlandırılabilir [2].

Her üç durum için kanal geometrisi ve tatlı su akım parametreleri sabittir. $\mathrm{Bu}$ üç senaryonun uygulanmasındaki amaç, kontrollü olarak koşulların ideale yakın bir durumdan oldukça karmaşık bir duruma doğru geçmesi ve bu olurken, geleneksel tasarım metodunun hangi noktada uygulanamaz hale geldiğinin belirlenmesidir. Buraya kadar anlatılan ve önişlem olarak adlandırılan süreçler ile tanımlanan modeller çalıştırılmış aşağıda sonuçlar taşkın yatağı tasarımı kapsamında değerlendirilecektir.

\section{Bulgu ve yorumlar}

1. Senaryo: Başlangıçta kanalın boş olduğu durum için çözüm yapılmıştır. Şekil 7'de bazı zaman aralıkları için kanal içerisindeki tatlı su akımının hacimsel ifadesi gösterilmiştir. 


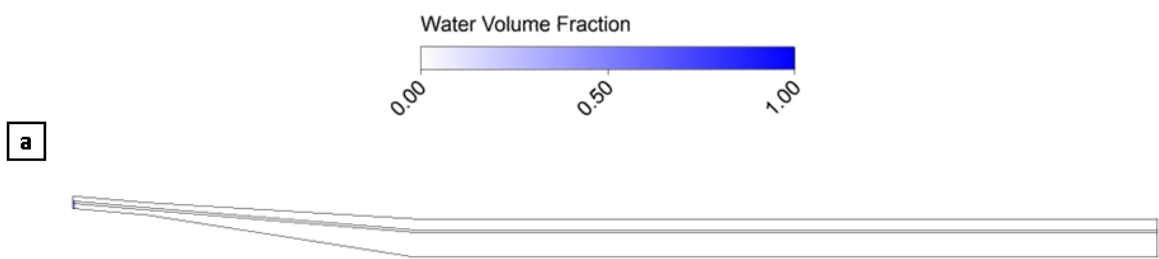

$\mathbf{b}$ $1 \Rightarrow$ hacmen $\% 100 \mathrm{su}$, volume fraction $=0 \Rightarrow$ hacmen $\% 0 \mathrm{su}$ ).

Yapılan çözüm sonucunda, istenilen zaman aralığında kanal geometrisinin herhangi bir noktasındaki tüm akım parametreleri gözlemlenebilmektedir. Şekil $8 \mathrm{a}$ ve 8 b'de sırasıyla çözümün 10. saniyesinde kanal cidarında oluşan basınç dağılımı ve kayma gerilmesi dağıllımı gösterilmiştir. Şekil 9'da ise kanalda oluşan maksimum kayma gerilmelerinin zamana bağl1 değişim grafiği gösterilmiştir. Bu parametre çözüm sırasında da referans parametresi seçilmiş ve yakınsama buradan dolaylı olarak da gözlemlenmiştir.

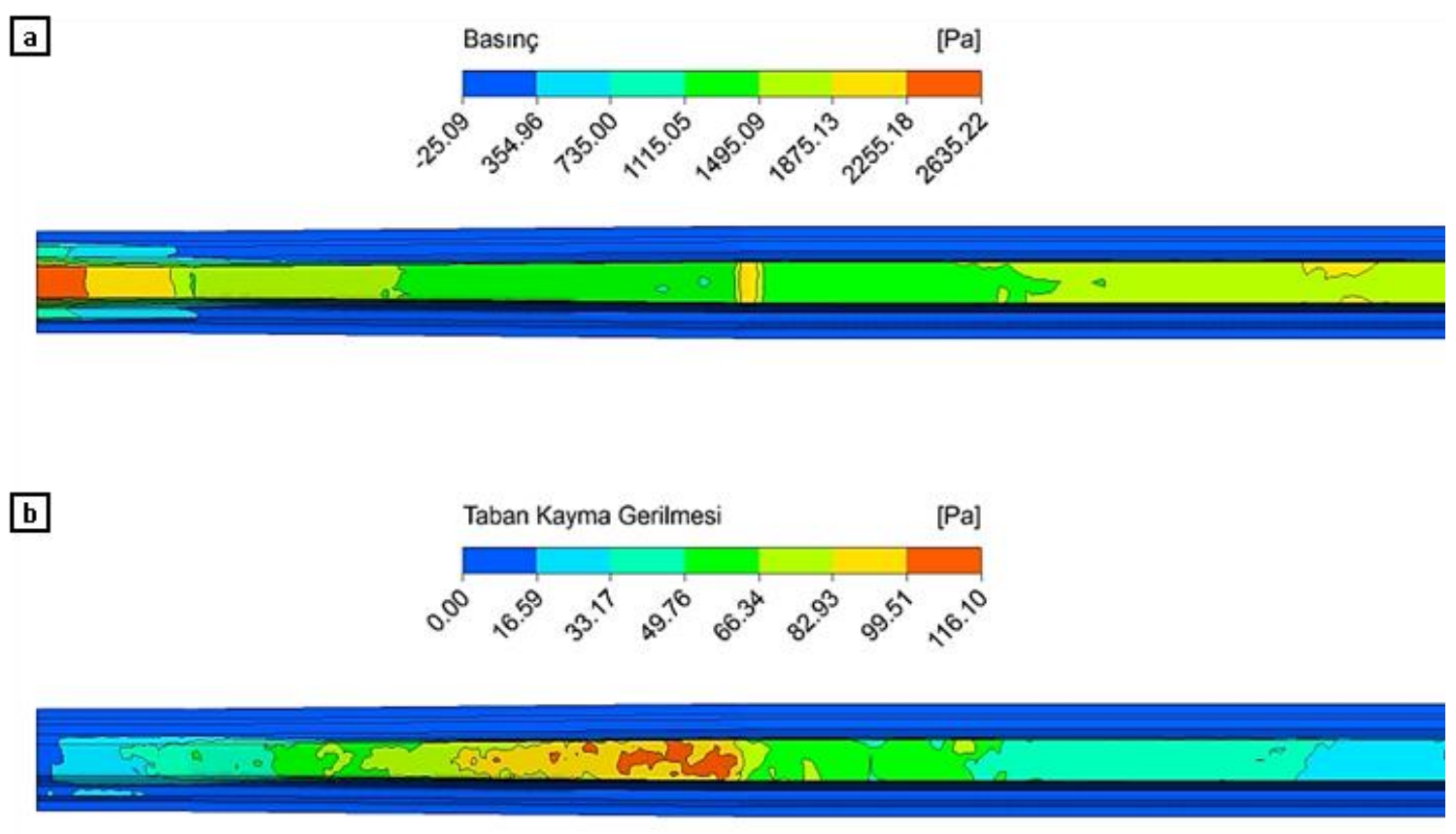

Şekil 8. 1. Senaryo a) Kanal cidarında oluşan basınç dağılımı alttan görünüm, t = $10 \mathrm{~s}$, b) Kanal cidarında oluşan kayma gerilmesi dağılımı alttan görünüm, $t=10 \mathrm{~s}$. 


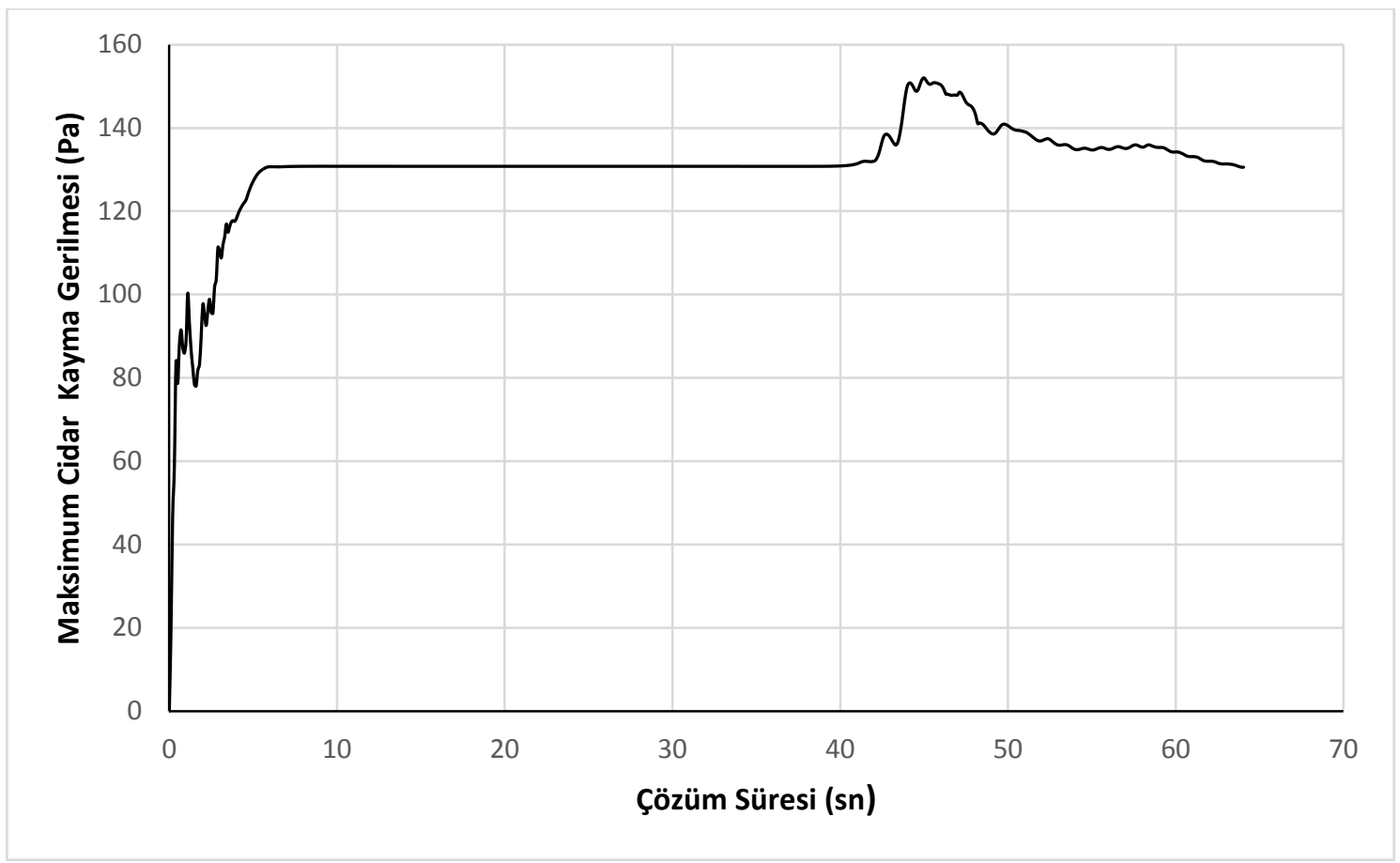

Şekil 9. Kanal cidarında oluşan maksimum kayma gerilmelerinin zamana bağlı değişimi.

2. Senaryo: Başlangıçta kanalda 1,1 m derinliğe sahip tatlı su bulunması ve girişten (inlet) tatlı suyun verilmesi durumu çözümlenmiştir. Yukarıda 1. Senaryo için verilen sonuçlar 2. Senaryo için de sırası ile Şekil 10, 11 ve 12 için verilmiştir.

a

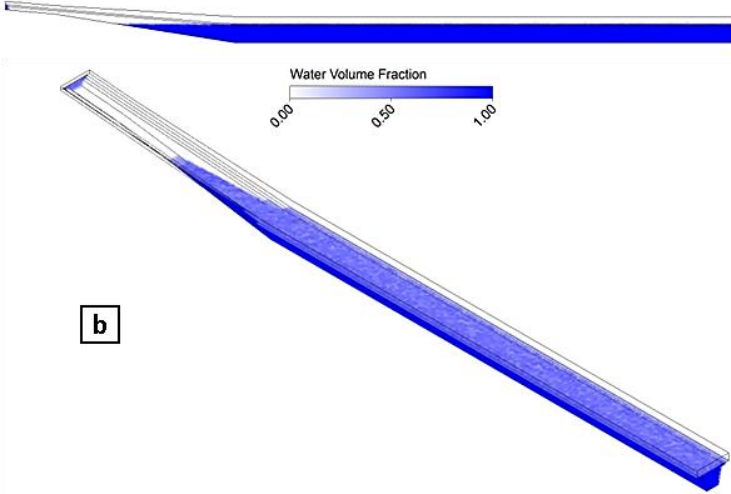

c

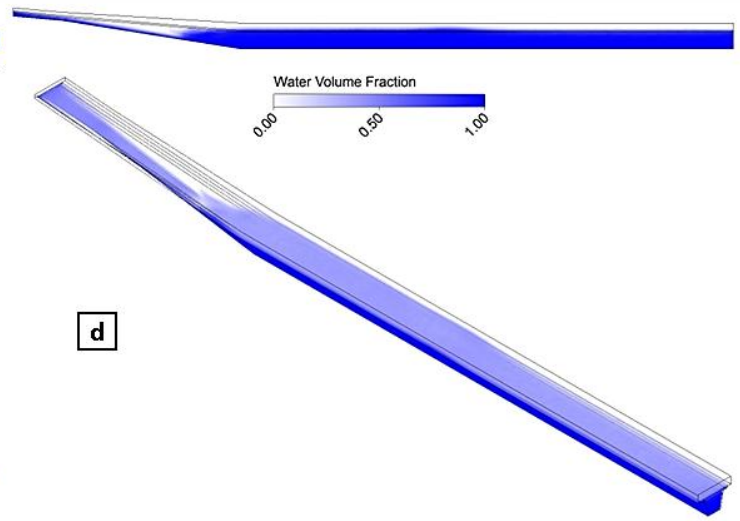

Şekil 10. 2. Senaryo için HAD akım simülasyonu. a) $t=0 \mathrm{~s}$ yan görünüm, $b) t=0 \mathrm{~s}$ genel görünüm, c) $\mathrm{t}=10 \mathrm{~s}$ yan görünüm, $\mathrm{d}$ ) $\mathrm{t}=10 \mathrm{~s}$ genel görünüm (volume fraction $=$ $1 \Rightarrow$ hacmen $\% 100 \mathrm{su}$, volume fraction $=0 \Rightarrow$ hacmen $\% 0 \mathrm{su})$. 


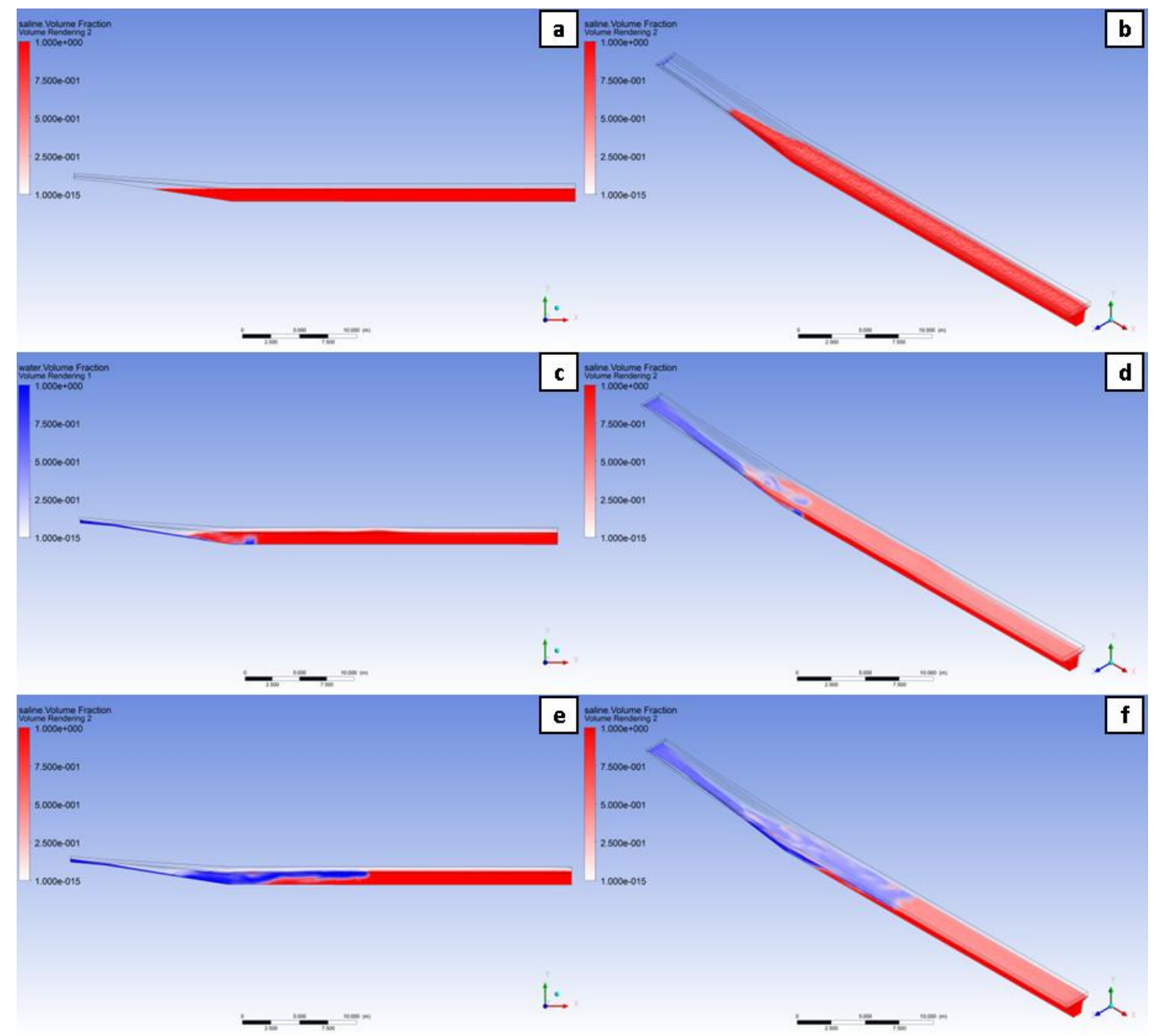

Şekil 13. 3. Senaryo için HAD akım simülasyonu a) $t=0 \mathrm{~s}$ yan görünüm, $b$ ) $t=0 \mathrm{~s}$ genel görünüm, c) $t=10 \mathrm{~s}$ yan görünüm, $d) t=10 \mathrm{~s}$ genel görünüm, e) $t=30 \mathrm{~s}$ yan görünüm, f) $\mathrm{t}=30 \mathrm{~s}$ genel görünüm (volume fraction $=1 \Rightarrow$ hacmen $\% 100 \mathrm{su}$, volume fraction $=0 \Rightarrow$ hacmen $\% 0 \mathrm{su})$.
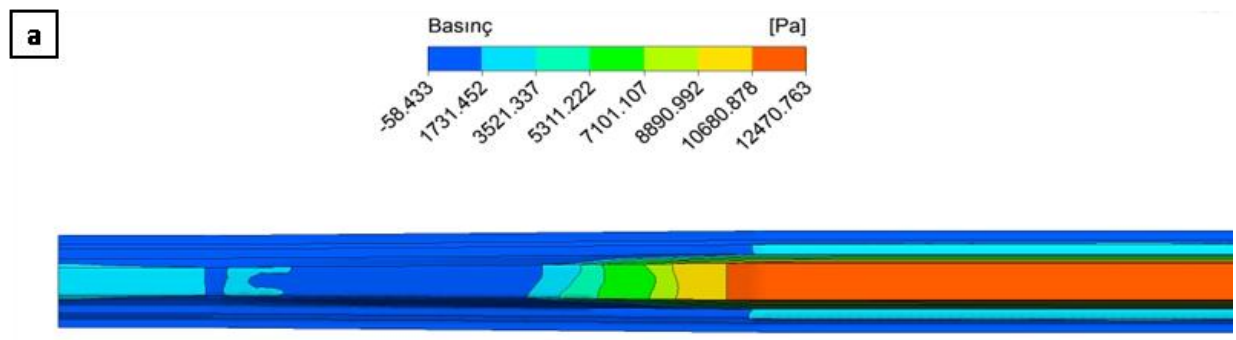

b
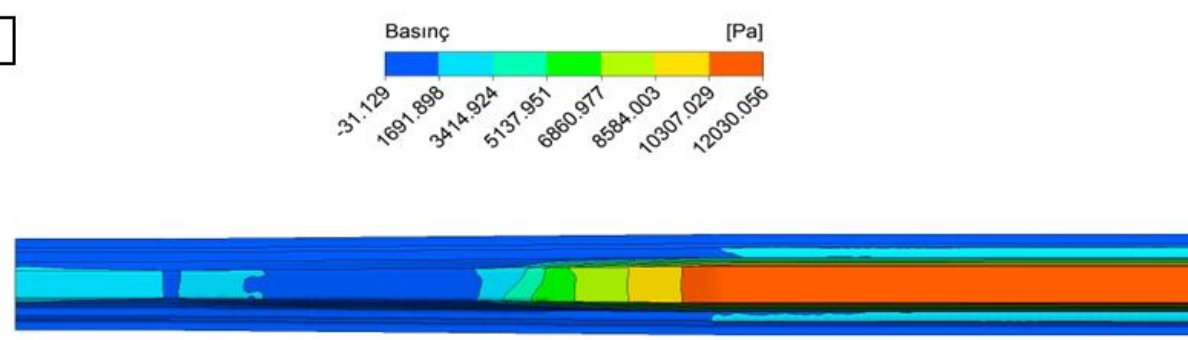

Şekil 14. Kanal cidarında oluşan basınç dağılımı alttan görünüm, a) $t=10 \mathrm{~s} \mathrm{~b}) \mathrm{t}=30 \mathrm{~s}$. 


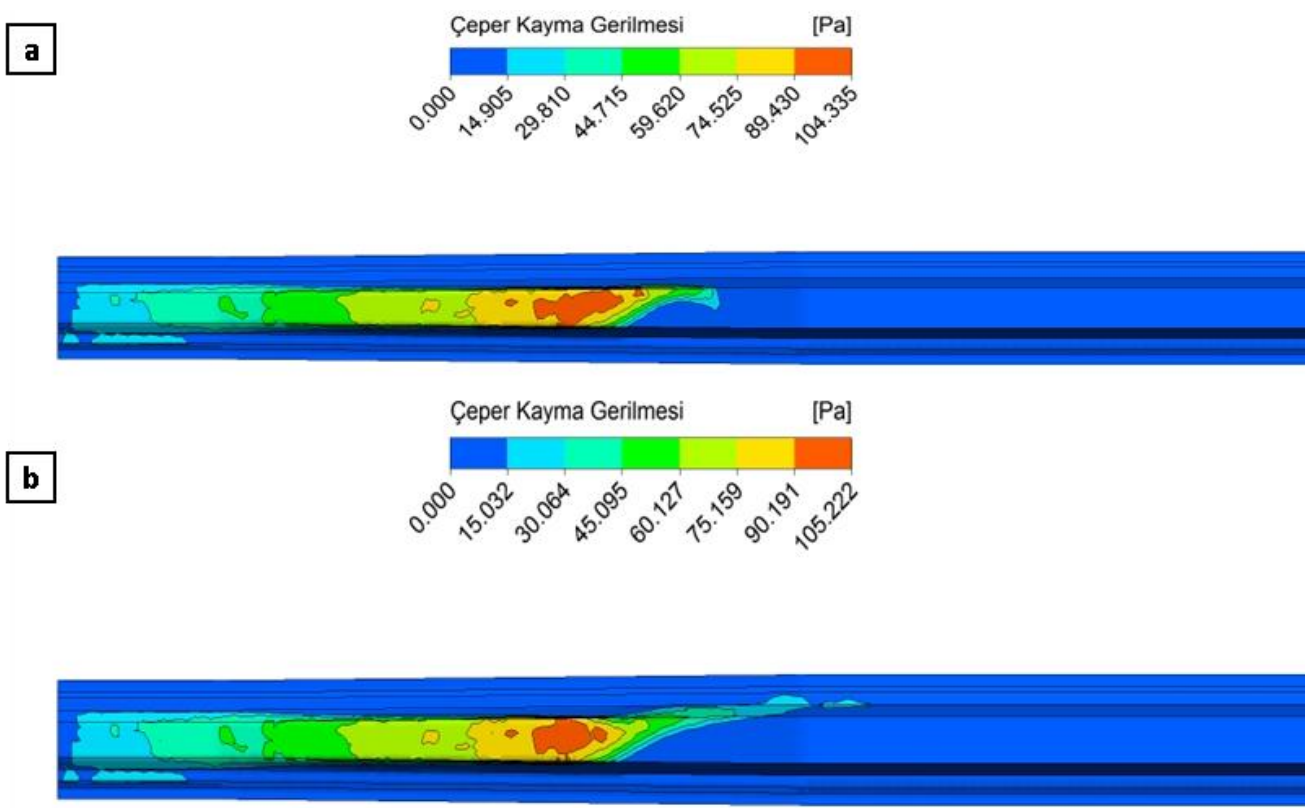

Şekil 15. Kanal cidarında oluşan kayma gerilmesi dağılımı alttan görünüm, a) $t=10 \mathrm{~s}$ b) $\mathrm{t}=30 \mathrm{~s}$.

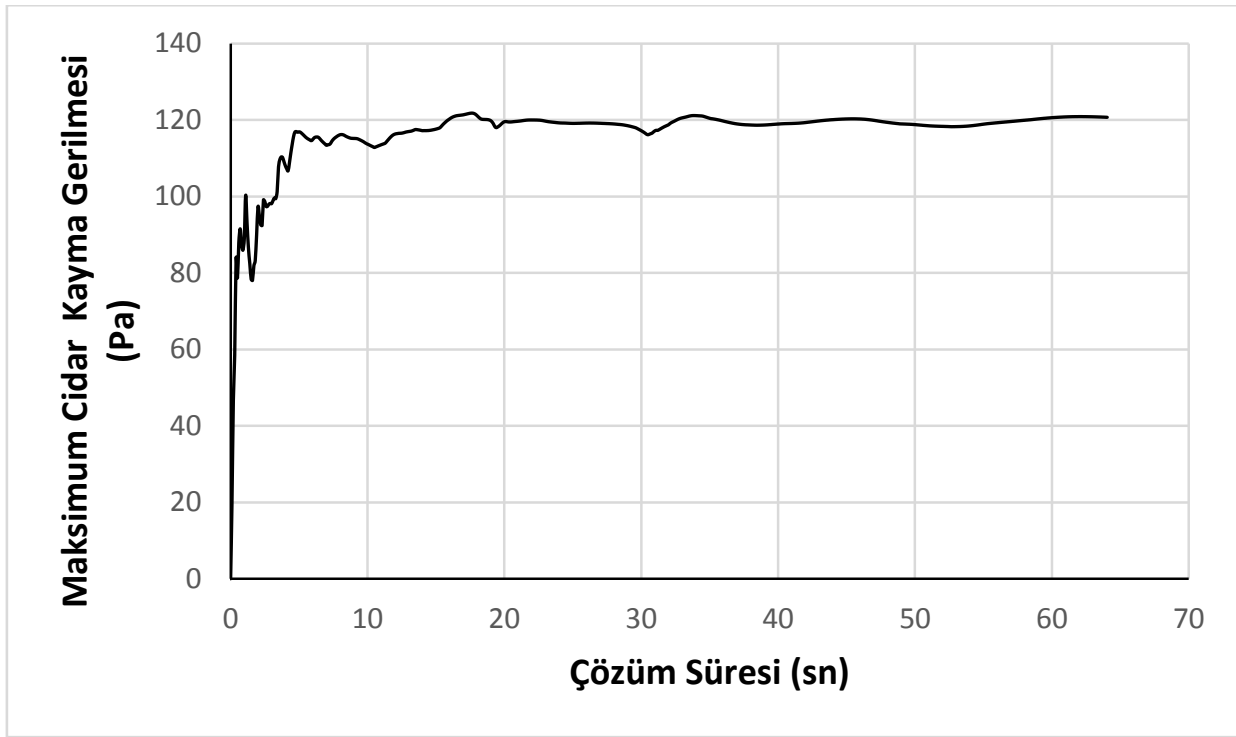

Şekil 16. Kanal cidarında oluşan maksimum kayma gerilmelerinin zamana bağlı değişimi.

\section{Sonuç ve öneriler}

Taban kayma gerilmesinin, $\tau_{0}$, en yüksek değeri, her üç senaryo için, eğimin aniden azaldığı 2. ve 3. bölge geçiş kısmında gözlenmiştir (Şekil 8, 11 ve 15). Taban kayma gerilmesinin en yüksek değerleri, zamanla değişimler de dikkate alınarak sırası ile 1, 2 ve 3. senaryolar için $130 \mathrm{~Pa}, 115 \mathrm{~Pa}$ ve $120 \mathrm{~Pa}$ olarak belirlenmiştir. Bu sonuca göre, tatl1-tatlı su karışım bölgesi ile tatl1-tuzlu su karışım bölgesin birbirine yakın (max) taban kayma gerilmelerine maruz kaldığı söylenebilir. Tabandaki kayma $\left(u^{*}\right)$ hızı bu senaryolar için $0.33-0.36 \mathrm{~m} / \mathrm{s}$ aralığında değişmektedir. 
Kanalın boş olduğu durumda verilen tatlı su akımının tabanda yarattığı durumda ise, diğer iki duruma göre \% 8'lik bir kayma gerilmesi artışı olduğu görülmektedir. Bu artış, uygulanan senaryolardan 1 . Senaryoda sığ ve hızlı bir akım, diğer iki senaryoda ise yüksek ataletli dere yatağını dolduran tatlı/tuzlu suyun akıma direnci ile açıklanabilir. Ayrıca, 3. Senaryoda dereden gelen tatlı suyun, dere yatağında bulunan tuzlu deniz suyu üzerinde, eğimin az olduğu bölgelerde tabakalı olarak akışa geçtiği gözlemlenmiştir (Şekil 13).

Yukarıda bahsedilen kayma gerilmesi ile ilgili artışa geri dönülecek olunursa, bu artış:

$\tau_{0}=\gamma R S$

kayma gerilmesi denklemi de göz önünde tutulursa, 1. Senaryo ile 1 ve 3. Senaryolar karşılaştırıldığında, hidrolik yarıçapta, sabit kanal taban eğimi için, \% 8'lik bir atış anlamına gelmektedir. 1. Senaryo, tasarım sırasında çok yaygın kullanılan bir kabuldür. Ancak, dere ağzı, 3 numaralı senaryoya ait koşulların yaşandığı bölgelerdir. Boş kanalda gözlemlenen durum çok düşük akım derinlikle karakterize edilebilir. Bu yüzden bu çalışmada da 1. Senaryo baz alınarak bir karşılaştırma yapılması olayın fiziğine aykırı olacaktır. Örnek vermek gerekirse, hidrolik yarıçapta \% 8 oranında bir artış, dikdörtgen kesitli bir kanalda, derinlik sabit tutulursa kanal genişliğinde 100 kat bir artışa karşılık gelmekte ve gerçekçi bir kabul olmadığı buradan anlaşılmaktadır. Zira çok geniş kanallarda hidrolik yarıçap, akım derinliği değerine ulaşmaktadır. $\mathrm{Bu}$ da dikkate alındığında kayma gerilmesinde küçük gibi görünen farklılıkların kanal genişliği tasarımını çok fazla etkileyeceği söylenebilir. Sonuç olarak özetlemek gerekirse, bu çalışmada değerlendirilen özel hallerde, konvansiyonel yaklaşımların yetersiz kalacağı görülmektedir. Akım koşullarının fiziksel ve/veya sayısal olarak modellenmesi bu açıdan önem kazanmaktadır.

$\mathrm{Bu}$ çalışmada amaç HAD modellemesi konusunda bir yenilik sunmak değil, aksine doğrulanmış ve kontrollü uygulanınca tatmin edici sonuçlar verdiği belirlenen modeller ile tasarım için kritik önemi olan çok özgün bir konuda inceleme ve yorum yapmak olarak nitelendirilebilir.

Burada uygulanan HAD modeli deneysel olarak doğrulanmamış ancak, literatürde doğrulanmış benzer çalışmaların hassas model kurma yöntemleri takip edilerek hazırlanmıştır. Model kurulumunda kullanılan sıvıların özellikleri ve bu farklı sıvılar arasındaki karakteristik kütle akısı, bu kütle akısının gerçekleştiği karakteristik ara yüz alanı gibi parametreler (bu çalışma için literatürden alınmıştır) karşılaştırmalı doğrulama deneyleri ile hassas olarak bulunmalıdır. Bunun yanında, limitleri türbülansa bağlı difüzyon ile genişletilebilecek olan açık kaynak kodlu yazılımlar daha hassas çözüm üretilebilmesi noktasında faydalı olabilecektir.

\section{Kaynaklar}

[1] Kim, S.E. ve Boysan, F., Application of CFD to environmental flows, Journal of Wind Engineering and Industrial Aerodynamics, 81, 145-158, (1999).

[2] Bombardelli, F.A., Cantero, M.I., Buscaglia, G.C. ve Garcia, M.H., Comparative study of convergence of CFD comercial codes when simulating dense 
underflows, In: Mecánica Computacional, G. Buscaglia, E. Dari ve O. Zamonsky (Eds.), 23, 1187 -1199, Bariloche, Argentina, (2004).

[3] Shteinman, B. ve Gutman, A., Flow turbulence and dispersion of different matter in the river mouth, Water Science and Technology, 27, (7-8), 397-404, (1993).

[4] Ofei, T.N. ve Ismail, A.Y., Eulerian-Eulerian simulation of particle-liquid slurry flow in horizontal pipe, Journal of Petroleum Engineering, dx.doi.org/10.1155/2016/5743471.

[5] Abdolkarimi, V. ve Ganji, H., CFD modeling of two immiscible fluids mixing in a commercial scale static mixer, Brazilian Journal of Chemical Engineering, 31, 4, 949-957, (2014).

[6] Georgoulas, P.A., Angelidis, P.B., Panagiotidis, T.G. ve Kotsovinos, N.E., 3D numerical modelling of turbidity currents, Environmental Fluid Mechanics, 10, 603-635, (2010).

[7] Hetland, R.D., The effects of mixing and spreading on density in near-field river plumes, Dynamics of Atmospheres and Oceans, 49, 37-53, (2010).

[8] Giardino, A., Ibrahim, E., Adam, S., Toorman, E.A. ve Monbaliu, J., Hydrodynamics and cohesive sediment transport in the Ijzer Estuary, Belgium: Case study, Journal of Waterway, Port, Coastal and Ocean Engineering, 135, 4, 176-184, (2009).

[9] Balakin, V.B., Hoffmann, A.C., Kosinski, P. ve Rhyne, L.D., Eulerian-Eulerian CFD model for the sedimentation of spherical particles in suspension with high particle concentrations, Engineering Applications of Computational Fluid Mechanics, 4, 1, 116-126, (2010).

[10] Socolofksy, S.A. ve Jirka, G.H., Environmentak fluid mechanics. Part I: Mass transfer and diffusion, Engineering Lectures, Universitat Karlsruhe, Germany, 2 nd Edition, (2002).

[11] ANSYS CFX Tutorials, Canonsburg, PA US, Release 12.1, (2009).

[12] ANSYS CFX-Pre User's Guide, Canonsburg, PA US, Release 15, (2013). 